\title{
Assessment of High- Temperature \\ Measurements for Use in the Gas Test Loop
}

\author{
S. Curt Wilkins \\ Robert P. Evans
}

May 2005

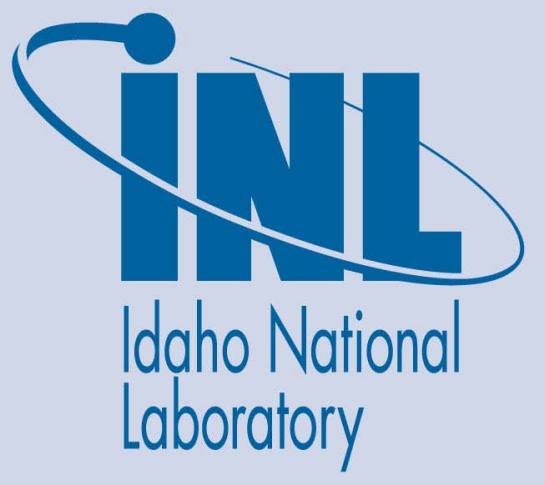

The INL is a U.S. Department of Energy National Laboratory operated by Battelle Energy Alliance 
INL/EXT-05-00298

\title{
Assessment of High-Temperature Measurements for Use in the Gas Test Loop
}

S. Curt Wilkins

Robert P. Evans

May 2005

\begin{abstract}
Idaho National Laboratory
Idaho Falls, Idaho 83415
\end{abstract}

Prepared for the

U.S. Department of Energy

Office of Nuclear Energy

Under DOE Idaho Operations Office

Contract DE-AC07-05ID14517 


\title{
Assessment of High-Temperature Measurements for Use in the Gas Test Loop
}

\author{
INL/EXT-05-00298
}

May 2005

Approved by:

Hans Gougar, Department Manager

Date

Wayne D. Ridgway, Project Manager

Date

Robert P. Evans

Date 


\begin{abstract}
Temperature transducers capable of control and test measurements in the 1400$1800^{\circ} \mathrm{C}$ range in the fast neutron irradiation environment of the Gas Test Loop are evaluated. Among the instruments discussed are high-temperature thermocouples, resistance temperature detectors, ultrasonic thermometers, noise thermometers, and optical temperature sensors. High-temperature capability, behavior under irradiation, technical maturity, cost, and availability are among the key factors considered in assessing the relative merits of each measurement method. In the near term, the doped molybdenum versus niobium-zirconium alloy thermocouple is deemed to be best suited to the in-pile test and control requirements. Additional characterization of this thermocouple combination is needed to ensure confidence in its performance. Use of tungsten-rhenium alloy thermocouples, with specific disadvantages noted, constitutes the recommended back-up position.
\end{abstract}

\title{
1.0 INTRODUCTION
}

The Gas Test Loop (GTL) project has as its current mission to provide a conceptual design for an apparatus that will allow irradiation testing of fuels, materials, and small components in a fast neutron spectrum in the Advanced Test Reactor (ATR). Key among the instrumentation needs of the GTL is a reliable means of temperature sensing that withstands the fast neutron environment and is suitable for both control of the GTL and temperature measurement in the test capsules.

This report examines available temperature sensing methods and assesses their technical maturity and suitability for application in the GTL, within the constraints of the technical and functional requirements as they are presently understood. Primary among the temperature sensors considered are both standard and non-standard noble and refractory metal thermocouples that are suitable for the GTL temperature range. Other sensing methods capable of operation through that temperature range are also examined. Included in the assessment, in addition to the temperature range, are behavior in both fast and thermal neutron environments, test environment and materials compatibility issues, and the degree of technical maturity of each candidate sensor.

\subsection{Required Functional Goals}

Functional requirements as presently outlined include measurement capability up to $1400^{\circ} \mathrm{C}$, with resolution of $\pm 5^{\circ} \mathrm{C}$ to $500^{\circ} \mathrm{C}$ and $\pm 1.0 \%$ above $500^{\circ} \mathrm{C}$. A minimum of 15 temperature data channels is needed.

The target fast neutron flux in the GTL is $1.0 \mathrm{E}+15 \mathrm{n} / \mathrm{cm}^{2} / \mathrm{s}$ (about $3 \mathrm{E}+22 \mathrm{n} / \mathrm{cm}^{2} /$ year). The fast to thermal flux ratio will be at least 15 and perhaps greater than 25 .

Booster fuel replacement is expected to occur every few weeks. Test capsules may be in place up to one year, and the design lifetime of the GTL is 20 years. 
There are no size constraints for instrumentation beyond the fact that the test volume is presently estimated at approximately $7 \mathrm{~cm}$ in diameter.

For control purposes, instrument time response should be less than one second.

Inert gas is the expected operating environment, although some test capsules may include liquid metal.

For thermal control, a data sampling rate of once per second or faster should be available. For experiment data archiving, a rate of once per hour or less may be adequate.

\subsection{Desired Functional Goals}

Extended goals for GTL tests include the desirability of temperature measurement capability up to $1800^{\circ} \mathrm{C}$, with resolution of $\pm 2.5^{\circ} \mathrm{C}$ to $1000^{\circ} \mathrm{C}$ and $\pm 0.5 \%$ above $1000^{\circ} \mathrm{C}$. A further desired goal is availability of 30 channels of temperature data.

\subsection{AVAILABLE TEMPERATURE SENSING METHODS: $1400-1800^{\circ} \mathrm{C}$}

\subsection{Thermocouples}

Standard and commercially-available thermocouple types capable of operation at the required $1400^{\circ} \mathrm{C}$ are limited to the platinum-rhodium alloys (Types $\mathrm{R}, \mathrm{S}$, and $\mathrm{B}$ ) and tungsten-rhenium alloys (unofficial designations Types $\mathrm{C}$ and $\mathrm{D}$ ). When the temperature range is extended to the desired $1800^{\circ} \mathrm{C}$, only the tungsten-rhenium alloy combinations are available. Discussion of the limitations and liabilities of these thermocouple types in reactor environments is included in Section 3.0.

Table 1 below lists the accepted tolerances for the standard thermocouple types discussed in subsequent sections. The limits of error listed cannot be assumed to be the measurement error for those thermocouple types in actual practice, but are only a guide for discussion between purchaser and supplier for bare, as-supplied wire. When establishing uncertainties for thermocouples used in specific configurations and environments, the tolerance for a given type constitutes just one of the uncertainty factors to be taken into account. The table is provided as a guide for judging the lower uncertainty limit for thermocouple measurements in comparison with the required and functional goals given in the previous section for GTL temperature measurements.

Tungsten-rhenium alloy Type C (W-5\% Re versus $\mathrm{W}-26 \% \mathrm{Re})$ and Type $\mathrm{D}(\mathrm{W}-3 \% \mathrm{Re}$ versus $\mathrm{W}-25 \% \mathrm{Re}$ ) employ thermoelements with melting points as high as $3350^{\circ} \mathrm{C}$. However, the electrical resistivity of the ceramic insulating materials commonly used in thermocouples decreases exponentially with increasing temperature. Low insulation resistance at high temperature consequently limits the practical temperature range for tungsten-rhenium alloy 
Table 1. Thermocouple tolerances, ASTM E230/ANSI MC 96.1 (Ref. [1])

\begin{tabular}{ccll}
\hline Thermocouple Type & Temperature Range, ${ }^{\circ} \mathrm{C}$ & $\begin{array}{c}\text { Limits of Error } \\
\text { Standard }\end{array}$ & $\begin{array}{c}\text { Limits of Error } \\
\text { Special }\end{array}$ \\
\hline $\mathrm{K}$ & 0 to $1250^{\circ *} \mathrm{C}$ & $\pm 2.2^{\circ} \mathrm{C}$ or & $\pm 1.1 \%$ or \\
& & $\pm 0.75 \%$ & $\pm 0.4 \%$ \\
$\mathrm{~N}$ & 0 to $1300^{\circ} \mathrm{C}$ & $\pm 2.2^{\circ} \mathrm{C}$ or & $\pm 1.1 \%$ or \\
& & $\pm 0.75 \%$ & $\pm 0.4 \%$ \\
R or S & 0 to $1450^{\circ} \mathrm{C}$ & $\pm 1.5 \mathrm{C}$ or & $\pm 0.6^{\circ} \mathrm{C}$ or \\
& & $\pm 0.25 \%$ & $\pm 0.1 \%$ \\
B & 600 to $1700^{\circ} \mathrm{C}$ & $\pm 0.5 \%$ & Not \\
& & & Established \\
$\mathrm{C}^{*}$ or $\mathrm{D}^{*}$ & 0 to $2320^{\circ} \mathrm{C}$ & $\pm 4.5^{\circ} \mathrm{C}$ or & Not \\
& & $\pm 1.0 \%$ & Established \\
\hline
\end{tabular}

* Not official symbol or designation

** Whichever value is greater

thermocouples to perhaps $2000^{\circ} \mathrm{C}$ in most cases. Even the highest quality instruments seldom operate reliably above $2200^{\circ} \mathrm{C}$, where electrical shunting due to low insulation resistance and open-circuit failure due to embrittlement of the thermoelements become progressively more serious problems.

Under thermal neutron irradiation, tungsten transmutes to rhenium and rhenium in turn transmutes to osmium, with the result that a compositional change and a corresponding calibration change occurs. Various experimenters have reported decalibrations ranging from -3 to $-15 \%$ of actual temperature for a thermal fluence of $1 \mathrm{E}+21 \mathrm{n} / \mathrm{cm}^{2}$ [2]. The effect of fast neutrons is difficult to separate from that of thermal neutrons in such tests. It is generally believed that fast neutron exposure produces lattice dislocations that produce an effect similar to that of cold working, an effect that anneals out at elevated operating temperatures. Attempts have been made to develop methods of predicting the decalibration as a function of fluence, with little success beyond applying a first-order correction based on the average of decalibration levels reported in the literature. Despite the best efforts of numerous investigators, accurate predict of transmutation decalibration remains an elusive goal because of the large number of interactive parameters.

A few thermocouple combinations considered to be suitable for use in irradiation environments have been used with some success on an experimental basis. Primary among these are Pt-5\% Mo versus Pt- $0.1 \% \mathrm{Mo}$ (available in the past as a custom product from Englehard Industries), pure $\mathrm{Mo}$ versus pure $\mathrm{Nb}$, and pure Mo versus $\mathrm{Nb}-1 \% \mathrm{Zr}$. The principal rationale for using these particular combinations is the low thermal neutron cross sections of the component metals. Schley and his co-workers [3] studied a range of molybdenum-niobium alloys to identify the optimum thermoelement pair based on thermoelectric properties, although those alloys were not employed for in-pile temperature measurements.

Many refractory metal combinations have been tested in laboratory settings in attempts to find thermocouples with properties superior to those of W-Re alloys for use at temperatures above about $1600^{\circ} \mathrm{C}$. Tungsten, rhenium, tantalum, niobium, molybdenum, iridium, ruthenium, and 
osmium (all having melting temperatures above $2000^{\circ} \mathrm{C}$ ) and their alloys have been studied in hundreds of combinations in a search for useful thermocouple properties. Many have suitable thermoelectric properties in the form of single-valued calibration curves of sufficiently high magnitude. A wide variety of problems, however, has been demonstrated with most of those metal combinations, with the result that none has been seriously pursued for general use.

\subsection{Ultrasonic Thermometers}

\subsubsection{Pulse-Echo Method}

One form of ultrasonic thermometer (UT) makes use of the change in acoustic velocity as a function of temperature in a metal rod. An acoustic pulse is launched in the rod by a magnetostrictive or piezoelectric transducer, and the time interval is measured between reflections from discontinues that define the length of the UT sensor. A plot of change in acoustic velocity versus temperature constitutes the UT calibration for a particular sensor. This method is usually referred to as the pulse-echo technique. The calibration usually varies slightly for different lots of the same metal, and calibration drift can occur as a result of grain growth in the sensor at high temperatures. Multiple sensor sections on a single UT probe allow the possibility of measuring temperature profiles with a single instrument. Tungsten, rhenium, or molybdenum sensors allow high-temperature measurements to near the melting temperature of the sensor. Most early UT efforts used tungsten or rhenium as the high-temperature sensing section. In irradiation environments, both suffer transmutation and decalibration similar to that experienced by tungsten-rhenium thermocouples [4]. Thoriated-tungsten has historically been the preferred sensor material by virtue of the retarding influence of $1-2 \%$ thoria on grain growth in tungsten at temperatures above about $1800^{\circ} \mathrm{C}$. Rhenium has also been used successfully, but both tungsten and rhenium are not attractive choices for reactor use because decalibration from transmutation is a problem similar to that experienced by W-Re alloy thermocouples under irradiation. Rhenium sensors decalibrated by as much as $-50 \%$ for a thermal neutron fluence of $1.2 \mathrm{E}+22 \mathrm{n} / \mathrm{cm}^{2}$ during in-pile tests at Oak Ridge National Laboratory (ORNL) [4]. The ORNL researchers believed that calibration corrections could be made based on calculations of the fraction of rhenium transmuted to osmium, but that goal was not actively pursued. Among refractory metals with low thermal neutron cross sections, both molybdenum and niobium have unacceptably small temperature coefficients of acoustic velocity to be of practical use as ultrasonic thermometer sensors [5].

Pulse-echo UTs were used with some success for fuel centerline temperature measurements in the Power Burst Facility (PBF) test series at the Idaho National Laboratory (INL) [previously the Idaho National Engineering and Environmental Laboratory (INEEL)] [6], and for similar applications at ORNL [4]. Sandia Laboratories [7], the Transuranium Institute in Karlsruhe, Germany [8], in FARO tests at Ispra, Italy, and in PHEBUS tests at the Cadarache laboratory in France. Implementation efforts are no longer underway in the first five instances and may not survive program and budget cuts at Cadarache. Further assessment of the state-of-the-art in UTs will be presented in Section 3.0.

\subsubsection{Acoustic Resonance Method}

An alternate UT technique uses the property of acoustic resonance in the sensor section at the end of a refractory metal or ceramic rod. Because the sensor dimensions vary with temperature, 
the resonant frequency then varies with temperature, as well. The driver frequency is adjusted until resonance occurs, and the resonant frequency is calibrated as a function of temperature. Bell and co-workers [9] at the University of Aston, England, identified molybdenum, platinum, iridium, and rhenium as viable sensor materials for this method, but they preferred sapphire (single-crystal alumina) for its reduced calibration drift at elevated temperatures. They reported successful laboratory tests at temperatures up to $1900^{\circ} \mathrm{C}$, with calibration stability of $\pm 2{ }^{\circ} \mathrm{C}$. Use of single-crystal alumina (melting point, $2050^{\circ} \mathrm{C}$ ) as the sensor material limits the instrument range to a maximum of something less than $2000^{\circ} \mathrm{C}$. Other UT investigators pursued pulse-echo techniques with refractory metal sensors for applications at temperatures as high as $3000^{\circ} \mathrm{C}$, largely as a means of extending the measurement range beyond the capability of tungstenrhenium alloy thermocouples. Bell, meanwhile, settled definitively on the use of sapphire sensors, and the resonant sensor technology, demonstrated only in a laboratory setting, simply never gained a following. Nothing published by Bell since 1985 could be located, and nothing was found published since 1975 on acoustic resonance thermometry. Thus, although sapphire UT sensors certainly meet the GTL requirements for temperature range, temperature sensitivity, and immunity to nuclear transmutation, the resonant sensor method is clearly an immature technology whose reconstitution requires extensive development in order to be viable.

Although the UT principle of operation is very simple, the materials required for hightemperature applications are expensive and the signal processing is complex and expensive to implement. Thus, from the standpoint of economics, UTs cannot generally be considered as competitive with passive instruments such as thermocouples.

\subsection{Optical/Fiber Optic Methods}

Commercially-available optical pyrometers are capable of measuring temperatures as high as $3000^{\circ} \mathrm{C}$. Visible-light pyrometers of the comparison, or "disappearing wire," type are limited to temperatures above about $700^{\circ} \mathrm{C}$ and have largely been replaced in recent years by infrared instruments capable of both low- and high-temperature measurements. Most modern pyrometers, however, are produced as a series of instruments that cover overlapping temperature ranges for greater accuracy, rather than a single broad range. For best results, a well-defined target is needed from which to collect radiant infrared energy for conversion to temperature measurements. It must be borne in mind that pyrometers are basically line-of-sight sensors, resulting in difficulty of application in many situations where an unobstructed viewing path to the target is impossible. Furthermore, it is generally impractical and imprudent to locate such optical sensors where they would be exposed to nuclear radiation - impractical because of the size of infrared sensors where limited space is available, imprudent because ionizing radiation can produce damage or parasitic signals in silicon, germanium, lead sulfide, and other contemporary infrared detector elements. Fiber optic cables have been used with some success in overcoming the line-of-sight limitation to transmit infrared radiation from the target to the detector element in non-nuclear applications. Under nuclear irradiation, however, optical fibers experience a progressive darkening that gradually blocks or absorbs the optical signal. Thus, instrument decalibration occurs with continued irradiation that eventually leads to a complete loss of signal. Further elaboration of this problem is included in Section 3.0. 


\subsection{Resistance Thermometers}

Resistance thermometers, commonly known as resistance temperature detectors (RTDs), use the change of electrical resistance of metals as a function of temperature. In principle, any metal can be used for such an application. However, only a few metals meet the requirements for suitable variation of electrical resistance. The majority of commercial RTDs use platinum sensors, which have a sufficiently large temperature coefficient of resistance (known as the $\alpha$ value) to provide good temperature resolution. Platinum RTDs have been developed to the point that temperatures can be measured to $0.01 \%$ or better in well-constructed instruments. Practical considerations, such as insulation resistance of lead cables and metallurgical stability at elevated temperature, result in application temperatures limited to about $660^{\circ} \mathrm{C}$.

Copper, nickel, and nickel-iron alloy RTDs are also commercially available, although in fewer configurations. They offer better temperature resolution (larger $\alpha$ values), but otherwise offer no particular advantage over platinum sensors beyond somewhat lower cost. The accepted temperature range for these three RTD types are -80 to $260^{\circ} \mathrm{C},-200$ to $260^{\circ} \mathrm{C}$, and -200 to $200^{\circ} \mathrm{C}$, respectively.

Tungsten has occasionally been used as an RTD sensor element for higher temperatures, but it is brittle and difficult to work with and, therefore, not a favored material [10]. The practical temperature range for tungsten RTDs is usually given as about -100 to $1200^{\circ} \mathrm{C}$ [11].

\subsection{Others}

For completeness, two further thermometry options are briefly discussed. However, the common base-metal thermocouples noted below cannot cover the needed temperature range for the GTL, and the Johnson Noise Power Thermometer is not sufficiently well developed for the temperatures of interest.

\subsubsection{Base-Metal Thermocouples}

First of all, it should be noted that Type $\mathrm{K}$ and Type $\mathrm{N}$ thermocouples are suitable for use in irradiation environments. The temperature range for reliable operation is below $1200^{\circ} \mathrm{C}$, however, for both types. Type K (Chromel versus Alumel is the most common alloy combination), in particular, has a history of successful application in reactor applications under fast and thermal neutron fluences as high as $2 \mathrm{E}+23 \mathrm{n} / \mathrm{cm}^{2}$ [12]. Fast neutron exposure has been reported to produce lattice dislocations with effects similar to those of work hardening, which can be annealed out at temperatures above about $500^{\circ} \mathrm{C}$ [13]. Comparable effects are generally believed to be the extent of fast neutron damage in all thermocouple materials. Of greater importance is the fact that increasingly greater drift as a function of time and temperature in the range of $900-1200^{\circ} \mathrm{C}$ limits the accuracy of metal-sheathed Type $\mathrm{K}$ thermocouples [14]. Therefore, the temperature range of operation has always proven to be a more significant factor in the lifetime and failure mode of Type $\mathrm{K}$ thermocouples than has either fast or thermal neutron exposure.

Type $\mathrm{N}$ thermocouples (Nicrosil and Nisil alloys) were developed with the aim of greater resistance to oxidation than that of Type $\mathrm{K}$ instruments [15]. Bare-wire Type $\mathrm{N}$ thermocouples in oxidizing environments have indeed proven to have greater oxidation resistance, but performance in metal-sheathed, mineral-insulated configurations has commonly been inferior to 
that of Type K instruments. Given the similarity of composition, performance of Nicrosil versus Nisil thermocouples under irradiation can be expected to be comparable to that of Type K instruments, with the same temperature limitations.

\subsubsection{Johnson Noise Power Thermometer (JNPT)}

Considerable effort was expended at the Oak Ridge National Laboratory (ORNL) to develop a thermometer based on the generation of random electrical noise in a heated metal. That noise, commonly referred to as Johnson noise, has low-level current and voltage properties that can be measured with sophisticated techniques. Historically, efforts to use Johnson noise measurement as a temperature sensing method have focused on measurement of the noise current alone or the noise voltage alone. In contrast, the ORNL technique used measurement of Johnson noise power, which turns out to be independent of the sensor resistance [16]. Independence of sensor resistance allowed the ORNL researchers to use a rhenium sensor in reactor applications without concern for the resistance change that occurs under thermal neutron irradiation. The goal was to eventually develop the JNPT technology to compete with ultrasonic thermometer technology for temperature measurements up to $3000^{\circ} \mathrm{C}$. That goal was not achieved for three primary reasons:

1. The sophisticated electronic signal processing for very low-level current and voltage measurements proved to be at least as costly as that required for ultrasonic thermometers,

2. The JNPT also proved to be susceptible to the same electrical shunting limitations in lead cabling as those that limit the temperature range of refractory-metal thermocouples, and

3. Johnson noise generated in the instrument lead cable is an error source that requires special compensation, adding to the instrument cost.

In practice, successful JNPTs have been reported for in-pile applications at temperatures up to $1500^{\circ} \mathrm{C}$ [17]. Brixy has also reported successful Johnson noise thermometers applications at about $850^{\circ} \mathrm{C}[18]$.

\subsection{ASSESSMENT OF MATURE TEMPERATURE SENSORS}

For reference purposes in assessment discussions of various high-temperature sensors, the following table is shown to illustrate the susceptibility to thermal neutron transmutation of component sensor materials. In irradiation situations, such as that of the GTL, low thermal neutron cross sections obviously are desirable for thermoelement materials. On the other hand, a thermocouple insulation material with a high thermal neutron capture cross section, such as hafnium oxide $\left(\mathrm{HfO}_{2}\right)$, can have a beneficial influence on the ratio of fast to thermal neutrons. 
Table 2. Thermal neutron capture cross sections and melting temperatures for high-temperature thermoelements and insulating materials.

\begin{tabular}{|l|l|l|l|l|l|l|l|l|l|}
\hline & $\mathrm{Pt}$ & $\mathrm{Rh}$ & $\mathrm{W}$ & $\mathrm{Re}$ & $\mathrm{Mo}$ & $\mathrm{Nb}$ & $\mathrm{Al}_{2} \mathrm{O}_{3}$ & $\mathrm{HfO}_{2}$ & $\mathrm{ZrO}_{2}$ \\
\hline $\begin{array}{l}\text { Thermal neutron } \\
\text { cross section, } \sigma, \\
\text { barns }\end{array}$ & 10 & 150 & 18.5 & 86 & 2.65 & 1.15 & 0.46 & 98.8 & 0.19 \\
\hline $\begin{array}{l}\text { Melting } \\
\text { temperature, }{ }^{\circ} \mathrm{C}\end{array}$ & 1770 & 1960 & 3410 & 3180 & 2610 & 2470 & 2040 & 2810 & 2710 \\
\hline
\end{tabular}

In general terms, the following information is useful for an understanding of the transmutation phenomenon in high-temperature thermocouples and the consequent decalibration effect. It was written by an individual known to and respected by the author and is quoted from Ref. [19] in a section entitled, "Selecting Thermocouples for a Nuclear Environment."

"For reactor instrumentation and control, accuracy and reliability of the temperature sensor are of utmost importance. Thermocouples are presently the only practical method of achieving in-core temperature measurements reliably. The accuracy of the thermocouples is directly related to the wire composition and to the time, temperature and exposure level to which it is subjected.

Neutron fluxes can cause compositional changes in the thermocouple wires. This reaction and transmutation of elements to different elemental isotopes causes changes in the thermoelectric output of the thermocouple. The amount of transmutation (change of one element to another) depends upon neutron velocity, neutron flux density, absorption cross section of the wire, the exposure time and the half lives of the isotopes.

In general, the slower the neutron, the higher is the probability of absorption. Thus, fast neutrons have lower chance of absorption and cause very little compositional change in the wire being irradiated when compared to an equivalent dose of thermal neutrons. They may be instrumental in causing lattice defects and temporary emf changes but these generally anneal out.

The probability of absorption has been measured experimentally for most elements and isotopes and can be expressed as neutron capture cross-section. This thermal neutron capture crosssection ... expressed in barns, shows only the relative probability of neutron absorption by that element. Transmutation from one element to another results when a nuclear reaction produces a radioactive isotope which decays into an isotope of a different element. Exact calculations of the transmutation products for the various elements found in thermocouples become involved because of the various multiple transmutations and half-lives of the isotopes involved.

Chromel (90 Ni-10 Cr) and Alumel (94\% Ni, [2\% Mn, 2\% Al]) are quite stable while constantan $(55 \mathrm{Ni}-45 \mathrm{Cu}$ ) is not so stable with about $10 \%$ of the copper converting to nickel and zinc over the 10 year period [at a thermal neutron flux of $\mathrm{E}+14 \mathrm{n} / \mathrm{cm}^{2} / \mathrm{s}$ ]. The alloys with rhenium, for example (W-W26Re, W5-W26Re, W3-W25Re), are poor and so are the platinum-rhodium alloys because of rapid transmutation of rhenium and rhodium (see Browning and Miller [20], cited in the text of Ref. [19]). 
Internal heating will occur in any material by absorption of gamma rays. This heating is proportional to the material mass (and thus density for a given configuration). In-core gamma heating rates of 5-15 watts/gm are common and should be considered in the thermocouple design."

A comprehensive reference on base-metal, noble-metal, and refractory-metal thermocouples, in both standard and non-standard combinations, and the degree to which many of those have been successfully applied in practice is that compiled by Kinzie [21].

Discussion of the specifics of decalibration of high-temperature thermocouples, with empirical results as reported by various investigators, follows.

\subsection{Platinum-Platinum/Rhodium Thermocouples}

Pt-10\% Rh versus Pt (Type S) and Pt-13\% Rh versus Pt (Type R) thermocouples are the two commercially available noble metal thermocouples to be considered. Two limitations in particular prevent extensive use of the platinum-rhodium versus platinum thermocouple types in reactor applications. First, the practical temperature range of both types is about $1400^{\circ} \mathrm{C}$, despite melting temperatures of the individual thermoelements up to $1860^{\circ} \mathrm{C}$ and standard calibration tables established up to $1690^{\circ} \mathrm{C}$. This limitation is the result of platinum's chemical reactivity with ceramic insulating materials, on one hand, and the tendency to excessive grain growth and susceptibility to high-temperature contamination of pure platinum, on the other hand. Grain growth in platinum at elevated temperatures, as with other pure metals, results in thermoelement fragility and susceptibility to open-circuit failure. Platinum fragility, however, occurs in the temperature range above about $1200^{\circ} \mathrm{C}$, as opposed to temperatures above about $1700^{\circ} \mathrm{C}$ for the tungsten- $3 \%$ or $5 \%$ rhenium alloys.

The second limiting factor is decalibration under nuclear irradiation. Platinum, although it has a relatively small thermal neutron capture cross section of 10 barns, nevertheless transmutes slowly to gold and then to mercury under irradiation. For thermal fluences between $\mathrm{E}+20$ and $\mathrm{E}+21 \mathrm{n} / \mathrm{cm}^{2}$, the change in composition does not result in a large thermoelectric decalibration. However, the mobility of mercury, even in small quantities, can seriously degrade the quality of insulating materials, producing reduced insulation resistance, at best, or a short between thermoelements, at worst.

Rhodium ( $\sigma=150$ barns) transmutes rapidly to palladium, and the compositional change in the positive Pt-Rh alloy thermoelement of both Type $\mathrm{R}$ and Type $\mathrm{S}$ instruments results in negative decalibration. Some examples of irradiation results from the literature will serve to show the extent of the transmutation problem. Calibration errors reported at ORNL for neutron fluences less than $\mathrm{E}+19 \mathrm{n} / \mathrm{cm}^{2}$ were within the measurement accuracy, but for fluences greater than $\mathrm{E}+20$ $\mathrm{n} / \mathrm{cm}^{2}$ errors exceeded negative ten percent [22].

Ehringer et al. [23] concluded from their computations of compositional changes that the platinum-rhodium thermocouples cannot be regarded as reliable after neutron exposures exceeding E+20 n/ $\mathrm{cm}^{2}$, although they made no estimates of the degree of thermoelectric decalibration. 
Hancock [24] reported decalibration of up to -5 percent per $1 \mathrm{E}+21 \mathrm{n} / \mathrm{cm}^{2}$ in thermal neutron environments for both Type $\mathrm{R}$ and Type $\mathrm{S}$ thermocouples.

Helm [25] reported an error of -14 percent in Pt-Rh thermocouples at $3.8 \mathrm{E}+21 \mathrm{n} / \mathrm{cm}^{2}$ for neutron energies exceeding $0.18 \mathrm{meV}$.

A third noble metal thermocouple is commercially available, Type B ( Pt-30\% Rh versus Pt-6\% $\mathrm{Rh}$ ). The thermoelectric signal is smaller than those of Types $\mathrm{R}$ and $\mathrm{S}$, but the useful temperature range is greater, up to $1800^{\circ} \mathrm{C}$ under ideal conditions. However, the fact that both thermoelements contain rhodium, with its large thermal neutron capture cross section, means that Type B thermocouples are considerably more susceptible to decalibration by transmutation than Types R and S. Thus, Type B is deemed to be unsuitable for long term reactor applications and little experimental irradiation data has been reported, as the increased rhodium content over that of Types R and S clearly will result in greater transmutation.

Frequent replacement of platinum-rhodium thermocouples might circumvent the problem of decalibration from transmutation in GTL applications. However, Types R and S operating near the GTL required temperature of $1400^{\circ} \mathrm{C}$ and Type B near the GTL desired temperature of $1800^{\circ} \mathrm{C}$ often experience open-circuit failure and material compatibility problems. Furthermore, the cost of platinum-rhodium thermocouple wire (as much as $\$ 40-50 /$ foot) may need to be taken into account when considering frequent replacement of Type $\mathrm{R}, \mathrm{S}$, or B thermocouples. In view of these factors, tungsten-rhenium alloy thermocouples may be more attractive than platinumrhodium instruments for replacement as a means of avoiding decalibration under irradiation for in-pile applications. Further discussion of factors relating to replacement of tungsten-rhenium alloy thermocouples can be found in later sections.

\subsection{Tungsten/Rhenium Alloy Thermocouples}

Little distinction is made between the $\mathrm{W}-3 \%$ Re versus $\mathrm{W}-25 \% \mathrm{Re}$ (so-called Type $\mathrm{D}$ ) and the $\mathrm{W}-5 \%$ Re versus W-26\% Re (so-called Type C) thermocouples, either in high-temperature applications in general or in investigations of irradiation effects. Both are now produced with doping of the low-rhenium alloy to stabilize grain growth at high temperature, and the calibration curves are not greatly different. The choice between the two often is reduced to the fact that Type $\mathrm{C}$ extension wires are available for compensation to $870^{\circ} \mathrm{C}$, while those used for Type $\mathrm{D}$ match the calibration to only $260^{\circ} \mathrm{C}$. Standard calibration tables have been established up to $2300^{\circ} \mathrm{C}$, with thermoelement melting temperatures as high as $3350^{\circ} \mathrm{C}$. Common problems encountered with W-Re alloy thermocouples include a high percentage of open-circuit failures resulting from thermoelement embrittlement, particularly during thermal cycling. Because the electrical resistivity of all insulating materials decrease exponentially with temperature, a point is reached at which thermocouple insulation becomes more-or-less conducting. Low insulation resistance in a thermocouple results in signal loss because of electrical shunting between the two wires and between the wires and a metal sheath, if present. In situations where the thermocouple extends beyond the peak of a temperature gradient, a phenomenon known as virtual junction formation occurs when insulation resistance is low, again resulting in loss of signal and indicated temperatures that are erroneously low. Such problems generally show up in W-Re alloy thermocouples in the range of $1800^{\circ} \mathrm{C}$, although special care in design, materials preparation, and fabrication has been seen in some instances to extend the useful range to as high as $2200^{\circ} \mathrm{C}$. 
There is no clear distinction between the transmutation effects under irradiation of one alloy combination in comparison to the other. Therefore, the discussion of transmutation and decalibration effects will be assumed to apply equally to both W-Re thermocouple types.

Tungsten, with a thermal neutron capture cross section of 18.5 barns, transmutes to rhenium $(\sigma=$ 86 barns), which in turn transmutes to osmium. Compositional changes thus occur rapidly in rhenium during in-pile use, with the consequent decalibration that accompanies that change. One study [2)] cited earlier collates the results reported by several investigators on the effects of WRe alloy thermocouple transmutation and decalibration. The preponderance of data analyzed in that study showed that decalibration errors ranged from -9 to -17 percent of actual temperature for a neutron fluence of $1 \mathrm{E}+21 \mathrm{n} / \mathrm{cm}^{2}$ thermal. Those results that extended to greater fluences indicated decalibrations of approximately -10 percent per $1 \mathrm{E}+21 \mathrm{n} / \mathrm{cm}^{2}$ thermal. Walter also plotted the decalibration against fast neutron fluence, with large scatter in the data and no conclusive correlation. Given the small fast neutron capture cross sections for thermocouple materials, which commonly range from millibarns to fractions of barns [26], that is not a surprising result.

A second report [27] by Halden scientists analyzed the results of several empirical tests and cited some of the same studies examined by Walter [2]. The Halden authors divided the various empirical results into two groups, one averaging -5.0 percent decalibration and the other -11.0 percent decalibration for a thermal neutron fluence of $1 \mathrm{E}+21 \mathrm{n} / \mathrm{cm}^{2}$. They were unable to identify parameters that would distinguish a particular test as belonging in one group or the other, however, highlighting the difficulties presented by the wide array of conditions that bear on the problem. Analysis of the osmium content of irradiated W-Re alloy wires correlated well with the computed predictions of Browning and Miller [20] and others, and led the Halden investigators to conclude that thermal neutron fluence can be taken as an independent variable in such studies. This point is significant because it supports the thesis that the observed decalibration can be separated from the level of fast neutron exposure. Their study further led them to believe that a fluence threshold of about $1 \mathrm{E}+20 \mathrm{n} / \mathrm{cm}^{2}$ thermal can be taken for detectable decalibration of WRe alloy thermocouples.

Decalibration of W-Re alloy thermocouples in the GTL might be avoided by replacing those thermocouples periodically, if the instrument configuration and position permits replacement. That is, if such thermocouples can be replaced before the thermal neutron exposure significantly exceeds $1 \mathrm{E}+20 \mathrm{n} / \mathrm{cm}^{2}$, then decalibration resulting from transmutation may be avoidable. Two further factors may influence a decision to replace thermocouples, however. First, W-Re alloy thermocouples are expensive, and the cost of frequent instrument replacement may need to be considered. Second, W-Re alloy thermocouples are notorious for their brittle nature and their consequent susceptibility to open-circuit failure, especially after (even short) periods of hightemperature operation. That failure mode is particularly frequent during thermal cycling. Failure frequency is typically inversely proportional to the thermocouple diameter; that is, the smaller the thermocouple diameter, the more likely is open-circuit failure. Thus, the likelihood of a high failure rate among $\mathrm{W}$-Re alloy thermocouples may lead to frequent instrument replacement in any case, whether the $1 \mathrm{E}+20 \mathrm{n} / \mathrm{cm}^{2}$ thermal fluence threshold is approached or not. 


\subsection{Platinum-Molybdenum Alloy Thermocouples}

As noted earlier, some work has been reported on Pt-Mo alloy thermocouples as a candidate for use in reactor environments because of the low thermal neutron capture cross sections of those metals. Specifically, custom alloys of Pt- $5 \%$ Mo and Pt $-0.1 \%$ Mo have been produced in the past by Engelhard Industries with the intent of finding a market for thermocouples suitable for use under nuclear irradiation.

Reichardt [28] was among the first to examine the Pt-5\% Mo versus Pt- $0.1 \%$ Mo thermocouple. A bare wire couple tested at $1300^{\circ} \mathrm{C}$ for 1000 hours in argon drifted 15 percent, probably caused by trace amounts of oxygen. Subsequent tests in argon and vacuum, with graphite present, resulted in no appreciable calibration drift at temperatures up to $1500^{\circ} \mathrm{C}$. Cunningham and Goldthwaite [29] reported substantial drift for thermocouples of this type in a reactor environment at $1540-1760^{\circ} \mathrm{C}$. They suggested contamination (residual oxygen?) as a possible cause. Schley [30] observed a negative drift of $4.6 \%$ at $1220^{\circ} \mathrm{C}$ for a thermal neutron fluence of $6.6 \mathrm{E}+20 \mathrm{n} / \mathrm{cm}^{2}$ in one such instrument and a positive drift in a second instrument of $1.5 \%$ at $1270^{\circ} \mathrm{C}$ and exposure of $4 \mathrm{E}+20 \mathrm{n} / \mathrm{cm}^{2}$ thermal. Both instruments failed during steady-state operation in-pile. One thermocouple was a swaged fabrication and the other a loose assembly, each with a sheath diameter of $1.8 \mathrm{~mm}$.

Differences of up to ten percent were reported between the calibration established by Engelhard Industries and those reported by various investigators for the $\mathrm{Pt}-5 \% \mathrm{Mo} / \mathrm{Pt}-0.1 \% \mathrm{Mo}$ thermocouple. The apparent sensitivity of this couple to oxygen, combined with variations in configuration and fabrication or test techniques, may account for such differences. Disparities in reported test behavior combine with thermoelement melting temperatures near $1800^{\circ} \mathrm{C}$ appear to render this thermocouple combination marginal, at best, as a candidate for the temperature range desired for the GTL.

\subsection{Molybdenum-Niobium Thermocouples}

Interest in Mo versus $\mathrm{Nb}$ thermocouples dates from the early 1960s, when W-Re thermocouple combinations were developed for high-temperature applications. Calibration work was reported by Fanciullo [3], Pletenetskii [32], and Zysk and Robertson [33]. As is common with pure metals, the thermoelectric properties of both molybdenum and niobium have been seen to be sensitive to contamination and grain growth. Work done by the author [34] found pure niobium to be embrittled after operation at temperatures up to $2200^{\circ} \mathrm{C}$ and thus highly prone to opencircuit failure. In an effort to ameliorate that problem, Knight and Greenslade [35] tested a Mo versus $\mathrm{Nb}-1 \% \mathrm{Zr}$ thermocouple in-pile at $1080^{\circ} \mathrm{C}$ for comparison with Type $\mathrm{K}$ and $\mathrm{W}-\mathrm{Re}$ alloy thermocouples. The calibration for this combination was essentially the same as that for pure Mo versus pure $\mathrm{Nb}$. For fast and thermal neutron fluences of $2.7 \mathrm{E}+21$ and $1.6 \mathrm{E}+21 \mathrm{n} / \mathrm{cm}^{2}$, respectively, stability of the $\mathrm{Mo} / \mathrm{Nb}-1 \% \mathrm{Zr}$ thermocouple was comparable to that of the Type $\mathrm{K}$ instrument (no discernible decalibration), whereas the W-Re alloy thermocouple decalibrated by approximately -10 percent.

Pure molybdenum recrystallizes at about $1300^{\circ} \mathrm{C}$, resulting in embrittlement from excessive grain growth. Doping techniques, similar to those used with tungsten, are commonly employed with molybdenum to increase the recrystallization temperature and retard grain growth. The 
classic method uses the addition of small quantities of silicon, tungsten, and potassium, and recent efforts rely on the addition of lanthanum oxide. Recent work at the INL [36] showed undoped Mo to be brittle in mandrel-wrap tests after 30 minutes at $1300^{\circ} \mathrm{C}$ in argon, and Mo wires doped by both of the above techniques were still ductile after 30 minutes at $1600^{\circ} \mathrm{C}$ when wrapped on a mandrel of twice the wire diameter. In continuing work, mandrel-wrap tests performed on 0.010 inch-diameter. Mo wires, doped with silicon, tungsten, and potassium, after periods of 240 minutes at $1700^{\circ} \mathrm{C}$, showed some lack of ductility, appearing to confirm that delay in recrystallization by this doping techniques is a function of both temperature and time at temperature. In comparison, 0.016-inch diameter lanthanum oxide doped Mo wires (supplied as a courtesy by Schwarzkopf Technologies) retained their ductility after 60 minutes at $1700^{\circ} \mathrm{C}$ in argon. In addition, Mo (doped with lanthanum oxide) 1.6\% niobium wires of 0.014 -inch diameter (supplied by Sylvania on an experimental basis) retained their ductility after the same test sequence.

Mandrel-wrap tests also were performed on pure $\mathrm{Nb}$ and $\mathrm{Nb}-1 \% \mathrm{Zr}$ wires of 0.010 inch diameter after periods of 30 and 60 minutes at $1700^{\circ} \mathrm{C}$ in argon. Both wire types were ductile when wrapped on a 0.020 inch-diameter mandrel. As noted earlier, pure $\mathrm{Nb}$ wires from the same lot of material calibrated at temperatures up to $2200^{\circ} \mathrm{C}$ were severely embrittled. Reasons for differences in behavior, beyond the temperature levels, have not yet been established.

Brief mention was made in Section 2.1 of the work reported by Schley and co-workers [3] on various Mo-Nb alloys. They undertook a careful, systematic study of those alloys as thermocouple candidates, based on the empirical observations of Crussard [37]. They looked for alloys with maximum thermoelectric output and temperature sensitivity, expecting furthermore that the alloys would show less sensitivity to contamination and drift than the pure Mo-Nb combination. Each alloy was studied and characterized individually as well as in combination with the other alloys. The choice of a positive thermoelement was clear-cut, but both $\mathrm{Nb}-10 \%$ $\mathrm{Mo}$ and $\mathrm{Nb}-40 \%$ Mo offered attractive properties. Their selection of Mo-5\% Nb versus Nb-10\% Mo was a compromise based on the combination's high-temperature emf, its temperature sensitivity above $1500^{\circ} \mathrm{C}$, and the anticipated fabricability of the alloys. The emf relationship of this alloy combination is similar to that of $\mathrm{W}$-Re alloy thermocouples up to about $1500^{\circ} \mathrm{C}$ and is about 20 percent larger than that of pure Mo versus pure $\mathrm{Nb}$ between 1500 and $2000^{\circ} \mathrm{C}$.

Hot-drawing of arc- and electron beam-melted billets of the two Mo-Nb alloys was not successful for the Mo-5\% Nb alloy, but was moderately successful for the $\mathrm{Nb}-10 \%$ Mo alloy [38]. Lagging interest in this thermocouple in France, however, resulted in discontinuance of work on its development. Plans to use alternate wire fabrication techniques were thus not carried out.

Superficially, the Mo-5\% Nb versus $\mathrm{Nb}-10 \%$ Mo combination has all the earmarks of an excellent high-temperature thermocouple suitable for use in irradiation environments. In the event that both alloys remain ductile after high-temperature exposure, in fact, this combination holds promise for replacing the $\mathrm{W}$-Re alloys for temperature measurement up to $2200^{\circ} \mathrm{C}$ in both reactor and non-reactor applications. Not only would the Mo-Nb alloys be less susceptible to open-circuit failure by virtue of superior ductility, they may also prove to be less expensive than alloys containing rhenium. 


\subsection{Ultrasonic Thermometers}

As discussed in Section 2.2, two methods of ultrasonic thermometry, the pulse-echo technique and the acoustic resonance technique, have been attempted in the past. The acoustic resonance method was never developed beyond the laboratory stage, was not extensively used, and is not a currently available technology. On the other hand, the pulse-echo method has been used in several in-pile applications, and the following discussion is directed entirely to those instances.

Although ultrasonic thermometers have been used in a number of reactor applications, including fuel centerline temperature measurement in PBF fuel rods at the INL, most of those applications were many years ago and the responsible technical personnel (with the exception of the present author) are no longer active or available. The two most recent applications, to the knowledge of the author, were for out-of-pile FARO tests at the Ispra laboratory in Italy and for in-pile PHEBUS tests at the Cadarache laboratory in France. The FARO test program has been terminated and the personnel who worked with UTs have been reassigned. The author was able to observe UT applications first-hand during a two-year period at the Cadarache laboratory. UTs are not fabricated at Cadarache, nor do expertise and facilities to do so exist there, but a sufficient number of instruments for the PHEBUS test series were purchased several years ago from the Transuranium Institute in Germany, where Dr. H. Tasman was responsible for that work. Dr. Tasman has since retired and the UT work that he pioneered there has been abandoned. Thus, despite the relatively extensive use of UTs in reactor applications, ultrasonic thermometry cannot be considered to be a well-developed technology in the sense that no ready source is presently known for fabrication of high-temperature UTs. Anyone undertaking UT fabrication and signal processing would need to expend considerable effort and expense to reconstitute the facilities and expertise to do so successfully.

Other disadvantages of UTs for GTL temperature measurements were touched on in Section 2.2, including the susceptibility of the preferred sensor materials for high-temperature use, tungsten and rhenium, to transmutation under irradiation, and the high cost of materials, fabrication, and signal processing.

\subsection{Optical Temperature Sensors}

As noted in Section 2.3, commercially-available optical and fiber optic systems are available for temperature measurement as high as $3000^{\circ} \mathrm{C}$. However, two primary limitations essentially eliminate such instruments for irradiation applications. First, optical methods are of necessity line-of-sight techniques, which is difficult to implement in reactor configurations. Second, measurement approaches using optical fibers to circumvent the line-of-sight problem suffer progressive loss of signal due to darkening of optical fibers under irradiation [39]. Further, attempts to correct fiber optic measurements have shown that corrections are specific to both the test configuration and the radiation spectrum [40]. It is generally acknowledged that more research and development is needed to obtain appropriate correction factors for radiation effects. Thus, the current state-of-the-art appears to be insufficient to apply optical or fiber optic methods to high-temperature measurements in the GTL. 


\subsection{SUMMARY OF MATURE TEMPERATURE SENSOR TECHNOLOGIES}

\subsection{Platinum-Platinum/Rhodium Thermocouples}

Investigation of the $\mathrm{Pt}-10 \% \mathrm{Rh}$ versus $\mathrm{Pt}$ (Type $\mathrm{S}$ ) thermocouple dates from the late nineteenth century and has long been the basis for various refinements of the International Practical Temperature Scale. The Pt-13\% Rh versus Pt (Type R) thermocouple developed historically (c. 1922) as a replacement for Type $S$ thermocouples manufactured using platinum wire with a significant, but at the time undetected, impurity level of iron. Both types were among the first to be standardized with letter designations and, by virtue of their commercial availability and widespread use are mature temperature sensors.

Types R and S, however, are deemed to be insufficient for GTL needs for the following primary reasons:

1. The standard calibration range is limited to $1690^{\circ} \mathrm{C}$.

2. In practical terms the temperature range is best limited to perhaps $1400^{\circ} \mathrm{C}$.

3. Rhodium's large thermal neutron cross section results in large decalibrations due to transmutation in reactor applications.

Because the Type B thermocouple (Pt-30\% Rh versus Pt-6\% Rh) contains more rhodium than Types $\mathrm{R}$ and $\mathrm{S}$, even larger decalibrations from transmutation can be expected. As noted earlier, frequent instrument replacement as a means of avoiding such decalibration is feasible, but offers no apparent advantage over a similar approach using tungsten-rhenium alloy thermocouples.

\subsection{Tungsten/Rhenium Alloy Thermocouples}

W-5\% Re versus W-26\% Re and W-3\% Re versus W-25\% Re thermocouples, unofficially designated as Type $\mathrm{C}$ and Type $\mathrm{D}$, respectively, are commercially available and in widespread use. The individual thermoelements have melting temperatures up to $3350^{\circ} \mathrm{C}$ and standard calibration tables have been established up to $2300^{\circ} \mathrm{C}$. High-quality W-Re alloy thermocouples can be used, as a rule of thumb, up to $2200^{\circ} \mathrm{C}$. More commonly, however, the practical range of reliable use is limited to $1800-2000^{\circ} \mathrm{C}$ because of low insulation resistance that results in electrical shunting and virtual junction phenomena. Limiting factors in applying W-Re alloy thermocouples for measurements in the GTL include the following:

1. A disproportionately high failure rate, primarily from open-circuited wires.

2. High cost, particularly in view of the need for frequent replacement.

3. Decalibration of -10 percent or more from nuclear transmutation for irradiation exposure above about $1 \mathrm{E}+21 \mathrm{n} / \mathrm{cm}^{2}$ thermal. 
4. Measurement uncertainty likely will not meet the Required Functional Goals for temperature measurements in the GTL, and will certainly not meet the GTL Desired Functional Goals.

These points do not necessarily disqualify W-Re alloy thermocouples for use in the GTL, but they do signal the need for relatively frequent instrument replacement. Considerations such as original and replacement thermocouple cost, ease or difficulty of replacement, and thermocouple failure (with the consequent loss of data) prior to scheduled or anticipated instrument replacement must be taken into account. Loss of data appears to be a particularly serious risk regarding instruments used for test control.

\subsection{Platinum-Molybdenum Alloy Thermocouples}

Pt-5\% Mo versus Pt- $0.1 \%$ Mo thermocouples have been used for reactor applications as low neutron cross section instruments, in attempts to avoid transmutation decalibration. The melting temperature of the two alloys is, for all practical purposes, that of platinum, $1770^{\circ} \mathrm{C}$. Although the thermoelements have been produced on a limited or custom basis in the past, they are not readily available at present and cannot be considered to be commercially available in the same sense as W-Re alloy and Pt-Rh/Pt thermocouples. The following additional points appear to make this thermocouple combination only a quasi-mature technology and unsuitable for GTL applications.

1. The temperature range of application appears to be limited to perhaps $1300^{\circ} \mathrm{C}$, in any case, lower than the range of use for Types R and S.

2. This alloy combination has been seen to experience calibration drift as a result of sensitivity to residual oxygen in the operating atmosphere.

3. Large disparities have been reported in experimental test results, both in-pile and out.

4. The calibration is not well-established, with frequent disagreement among investigators and the alloy manufacturer, Engelhard Industries.

\subsection{Molybdenum-Niobium Thermocouples}

Molybdenum and niobium have long been attractive as candidate thermoelements for a thermocouple that is immune to transmutation and consequent decalibration in reactor environments. Both have low thermal neutron capture cross sections and high melting temperatures, two prerequisites for a thermocouple to be used under neutron irradiation at temperatures as high as $1800^{\circ} \mathrm{C}$ and perhaps higher. Problems related to thermoelement embrittlement have been ameliorated by the use of doped molybdenum and $\mathrm{Nb}-1 \% \mathrm{Zr}$, each of which has been reported to show improved ductility compared to the pure metal. These two thermoelement materials are commercially available, but they are not commercially produced in the form of finished thermocouples. Thus, Mo versus $\mathrm{Nb}-1 \% \mathrm{Zr}$ thermocouples are not a mature technology to the same degree as $\mathrm{Pt}-\mathrm{Rh} / \mathrm{Pt}$ and $\mathrm{W}-\mathrm{Re}$ alloy thermocouples. Work currently underway, however, indicates promise for the $\mathrm{Mo} / \mathrm{Nb}-1 \% \mathrm{Zr}$ combination for high-temperature measurement. 
Among the positive features now well-established about $\mathrm{Mo} / \mathrm{Nb}-1 \% \mathrm{Zr}$ thermocouples are:

- Virtual immunity to transmutation under neutron irradiation.

- An emf-temperature relationship comparable to that of Type $\mathrm{S}$ thermocouples.

- Good compatibility with candidate insulating materials.

- Good thermoelement ductility up to $1700^{\circ} \mathrm{C}$ for time periods of at least 60 minutes.

- Relatively inexpensive, commercial available thermoelements.

Still remaining to be better understood concerning the $\mathrm{Mo} / \mathrm{Nb}-1 \% \mathrm{Zr}$ thermocouple are the following points.

1. Lot-to-lot calibration repeatability for various wire suppliers.

2. Calibration stability at high temperatures for extended time periods.

3. Reliability -- resistance to open-circuit failure -- for extended time periods.

4. Thermocouple characteristics and behavior above $1600^{\circ} \mathrm{C}$.

The Mo-5\% $\mathrm{Nb}$ and $\mathrm{Nb}-10 \%$ Mo alloys recommended by Schley [3] are not commercially available in any form at present. Further discussion of potential future development of a more advanced molybdenum-niobium thermocouple system employing such alloys is discussed in Section 5.2.2.

\subsection{Ultrasonic Thermometers}

Refractory metal UTs employing the pulse-echo method, despite the fact that they have been used with some success in the past, are a less well-established technology at present than was the case some twenty years ago. Whereas there were several UT investigators and users who applied tungsten and rhenium sensors during that time period, no one, to the author's knowledge, is currently actively pursuing such instrumentation and much of the expertise acquired has now either been lost or is outdated in view of the signal processing technology currently available. Viable UT instrumentation could be reconstituted with sufficient effort and funding, but the following limitations would still present difficulty.

1. Tungsten and rhenium UT sensors are subject to composition and calibration change resulting from transmutation in a thermal neutron irradiation field.

2. Other low cross section refractory metals, such as molybdenum and niobium, are unsuitable for UT sensors by virtue of the small change in acoustic velocity with temperature. Alumina or sapphire has not been extensively investigated as a pulse-echo sensor material. 
3. Development of a new generation of signal processing hardware (and perhaps software) must be accomplished.

3. UTs are by nature an expensive form of instrumentation, even compared with W-Re alloy thermocouples.

As noted in Section 2.2, acoustic resonance UT technology is attractive for the GTL requirements, but it is a technology that existed only as a developmental method not currently available.

\subsection{Optical Temperature Sensors}

Radiation temperature sensors in the form of optical pyrometers, in line-of-sight configurations or in combination with optical fibers, are well-developed and are commercially available. Instruments are available covering the range from infrared temperatures to $3000^{\circ} \mathrm{C}$, usually at moderate cost. However, such instruments appear to be unsuitable for measurement of GTL temperatures for the following reasons.

1. Line-of-sight instruments are generally difficult or impossible to implement in reactor situations.

2. Optical fibers, used to circumvent the line-of-sight problem, suffer progressive darkening and loss of signal in nuclear environments.

3. Correction factors for darkening of optical fibers are case- and radiation spectrumspecific, requiring extensive evaluation for the particular conditions and configuration imposed upon the instrument.

The comparative effects of fast and thermal neutrons on optical fiber darkening have not been studied for various optical fiber compositions. Thus, the conditions noted in c) above indicate that further evaluation is necessary to judge the value of frequent replacement of optical fibers as a means of ameliorating signal loss from darkening during in-pile use.

\subsection{RECOMMENDATIONS}

\subsection{Tungsten/Rhenium Alloy Thermocouples}

As noted in Section 4.2 above, the disadvantages inherent to W-Re alloy thermocouples do not disqualify them out of hand for application in the GTL. However, decalibration from transmutation of both $\mathrm{W}$ and Re and the expected high failure rate must be given careful consideration. These factors lead to 1) the necessity of frequent instrument replacement and 2) near-certain loss of data from control instruments when W-Re alloy thermocouples fail during operation. Both factors must be given major weight in a decision to attempt use of such thermocouples, as must the costs accruing to instrument replacement.

The author's view is that use of W-Re alloy thermocouples should be taken as the back-up position for GTL temperature instrumentation. 


\subsection{Molybdenum-Niobium Thermocouples}

\subsubsection{Molybdenum vs. Niobium-1\% Zirconium}

Although the Mo versus $\mathrm{Nb}-1 \% \mathrm{Zr}$ thermocouple is not commercially available, it offers sufficient promise, in the opinion of the author, to warrant further examination and development for the GTL and other in-pile applications. Work to date on this thermocouple combination indicates strong potential for improvement in each of the three major weaknesses noted earlier for W-Re alloy thermocouples - reliability, cost, and decalibration. Improvement in the last two factors, in fact, are virtually certain at this point, given the high cost of W-Re alloy wires (typically \$20-25/foot versus \$2-3/foot for Mo and $\mathrm{Nb}$ wires) and the comparative neutron capture cross sections of the metals involved. Still to be determined is the comparative reliability of $\mathrm{Mo} / \mathrm{Nb}-1 \% \mathrm{Zr}$; the resistance to open-circuit failure during thermal cycling is of particular interest. Preliminary results from current work involving ductility as determined from mandrelwrap tests indicate that doped molybdenum is likely superior to $\mathrm{W}-5 \% \mathrm{Re}$ in terms of ductility after high-temperature heating. Thus, the doped $\mathrm{Mo} / \mathrm{Nb}-1 \% \mathrm{Zr}$ combination should be better than either W-Re alloy combination under the same conditions. In view of the superiority of the doped Mo-Nb alloy combination in terms of cost and in-pile decalibration, at least two of the three factors cited above weigh in favor of the doped Mo-Nb alloy over W-Re thermocouples.

Previous sections have noted continuing efforts at the INL to characterize and select candidate materials for a low cross section thermocouple suitable for in-pile use. Preliminary indications are that the combination of Mo with $\mathrm{Nb}-1 \% \mathrm{Zr}$ is the leading candidate. Several characteristics remain to be evaluated before the Mo versus $\mathrm{Nb}-1 \% \mathrm{Zr}$ thermocouple is qualified for GTL use. Among those areas are the following:

1. Lot-to-lot calibration repeatability for both $\mathrm{Mo}$ and $\mathrm{Nb}-1 \% \mathrm{Zr}$ wires.

2. Calibration stability at temperatures between $1400^{\circ} \mathrm{C}$ and $1800^{\circ} \mathrm{C}$.

3. Long-term thermoelement ductility at temperatures of $1400-1800^{\circ} \mathrm{C}$.

4. (Related to 2.), heat treatment of thermoelement wires prior to thermocouple fabrication to stabilize grain growth and calibration.

5. Reliability during thermal cycling, which is of particular interest in comparison to W-Re alloy thermocouples.

6. Actual performance under ATR irradiation.

The needs for temperature measurement in the GTL are clearly understood to be the immediate interest in assembling this assessment. However, on another level, development of the doped Mo-Nb alloy thermocouple in one form or another is potentially of significant importance for high-temperature measurement in general. Given the disadvantages of W-Re alloy thermocouples, the opportunity exists for a significant contribution to the state-of-the-art in hightemperature thermometry. In the view of the author, implementation of the doped $\mathrm{Mo} / \mathrm{Nb}-1 \% \mathrm{Zr}$ thermocouple combination constitutes an important first step toward development of a refractory 
metal thermocouple that can replace the current W-Re alloy combinations in all applications, nuclear or otherwise, up to perhaps $2000^{\circ} \mathrm{C}$. Discussion of the ultimate product toward that end follows in the next section.

\subsubsection{Molybdenum/5\% Niobium vs. Niobium $/ 10 \%$ Molybdenum}

Earlier sections have noted the investigation of Schley et al. [3] to determine doped $\mathrm{Mo} / \mathrm{Nb}$ alloys that are superior to pure molybdenum and rhenium as thermocouple materials. Their immediate goal, given the intractable problems encountered with tungsten-rhenium alloy thermocouples for in-pile temperature measurements, was to find an optimum thermocouple combination capable of measurements up to $2200^{\circ} \mathrm{C}$ in neutron irradiation fields. Even Schley and his co-workers likely did not fully realize at the time (c. 1978) the potential of their work for a high-temperature thermocouple suitable for replacement of tungsten-rhenium alloy thermocouples, whether in nuclear or non-nuclear temperature applications.

As discussed in Section 4.2, three major disadvantages commonly encountered with tungstenrhenium alloy thermocouples are high cost, high failure rates, and transmutation under irradiation. Present indications are that at least two of those shortcomings can be significantly improved upon by using even common, commercially available molybdenum and niobium or niobium-zirconium alloy wires as high-temperature thermoelements. High failure rates from thermoelement embrittlement at high temperature and during thermal cycling may be reduced by the use of molybdenum-niobium alloys. In addition, the results from Schley [3]. Doping techniques of the type used in tungsten and molybdenum production offer an additional avenue for exploration with regard to molybdenum-niobium alloys.

Although further refinement and characterization of the doped Mo versus $\mathrm{Nb}-1 \% \mathrm{Zr}$ thermocouple combination should constitute a worthy solution for the immediate needs of the GTL, it should be deemed as only an interim stage in the long-term view of temperature measurement technology, in the opinion of the author. Development of the molybdenumniobium alloys studied by Schley et al., should they prove to be fabricable as wires that retain their ductility, would open the way for commercialization of a high-temperature thermocouple that is attractive as an alternative to tungsten-rhenium alloy thermocouples for in-pile applications, if not as an across-the- board replacement.

A common interest clearly exists in various programs for a high-temperature thermocouple that is immune to nuclear transmutation. The GTL and other ATR tests, the Very High Temperature Gas-Cooled Reactor, the space reactor, and naval propulsion systems might all employ a standardized molybdenum-niobium alloy thermocouple, were it available. Many -- perhaps most -- industrial applications would likely adopt a standardized thermocouple that offers improved reliability and lower cost. Interested parties could profitably encourage molybdenum and niobium alloy producers to develop the necessary molybdenum-niobium alloys, showing the breadth and depth of the potential commercial market for the new thermocouple. 


\section{REFERENCES}

1. See, for example, on-line edition of Omega Industries catalog, page H-4.

2. A. J. Walter, "Thermocouple Calibration: Irradiation and Transmutation Effects," International Colloquium on High Temperature In-Pile Thermometry, EUR-5395, p. 428c, 1975.

3. R. Schley and G. Metauer, "Thermocouples for Measurements Under Conditions of High Temperature and Nuclear Radiation," Temperature: Its Measurement and Control in Science and Industry, Vol. 5, Part 2, p. 1109, 1982.

4. R. L. Shepard et al., "Ultrasonic and Johnson Noise Fuel Centerline Thermometry," International Colloquium on High-Temperature In-Pile Thermometry, EUR-5395, p.737, 1975.

5. G. A. Carlson and H. G. Plein, "Refractory Metals for Ultrasonic Thermometry Application," Sandia Laboratories, NUREG/CR-0368, SAND78-1382, 1978.

6. A. E. Arave, F. E. Panisko, and J. A. Christensen, "High Temperature Ultrasonic Thermometry -- In-Reactor Fuel Rod Centerline Temperature Test Results," ANCR-1091, 1972.

7. G. A. Carlson and H. G. Plein, "An Ultrasonic Thermometry System for Measuring Very High Temperatures in Reactor Safety Experiments," SAND79-0621, 1979.

8. H. A. Tasman et al., "Ultrasonic Thin-Wire Thermometry for Nuclear Applications," Temperature: Its Measurement and Control in Science and Industry, Vol. 5, Part 2, p. 1191, 1982.

9. J. F. W. Bell, A. A. Fathimani, and T. N. Seth, "An Ultrasonic Thermometer Using a Resonant Sensor," International Colloquium on High-Temperature In-Pile Thermometry, EUR-5395, p.649, 1975.

10. See, for example, on-line edition of Omega Industries catalog, page Z-34.

11. See, for example, eFunda.com.

12. W. E. Chapin, J. E. Drennan, and D. J. Harman, "The Effect of Nuclear Radiation on Transducers," REICH Report No. 43, Radiation Effects Information Center, 1966.

13. M. B. Herskovitz and H. H. Hubbell, Jr., "Effects of Fast-Neutron Irradiation on Sheathed Chromel/Alumel Thermocouples," ORNL/TM-3803, 1976.

14. R. L. Anderson et al., "Decalibration of Sheathed Thermocouples," Temperature: Its Measurement and Control in Science and Industry, Vol. 5, Part 2, p. 977, 1982.

15. N. A. Burley et al., "The Nicrosil Versus Nisil Thermocouple: A Critical Comparison with the ANSI Standard Letter-Designated Base-Metal Thermocouples," Temperature: Its Measurement and Control in Science and Industry, Vol. 5, Part 2, p. 1159, 1982.

16. C. J. Borkowski and T. V. Blaylock, "A New Method of Johnson Noise Thermometry," Review of Scientific Instruments, Vol. 45, No. 2, p. 151, 1974. 
17. M. C. Decreton, L. Binard, C. Delrez, W. Hebel, and W. Schubert, "High Temperature Measurements by Noise Thermometry," High Temperatures-High Pressures, Vol. 12, p. 395, 1980.

18. H. G. Brixy, "Temperature Measurement in Nuclear Reactors by Noise Thermometry," Nuclear Instruments and Methods, Vol. 97, p. 75, 1971.

19. SEMPAK catalog, SEMCO, Inc., North Hollywood, CA.

20. W. E. Browning, Jr., and C. E. Miller, Jr., "Calculated Radiation Induced Changes in Thermocouple Composition," Temperature: Its Measurement and Control in Science and Industry, Vol. 3, Part 2, Reinhold, New York, p. 271, 1962.

21. P.A. Kinzie, Thermocouple Temperature Measurement, John Wiley \& Sons, New York, 1973.

22. "Instrumentation and Controls Division Annual Report for Period Ending July 1, 1959," Oak Ridge National Laboratory, Oak Ridge, TN, TID-4500, $15^{\text {th }}$ Edition, November 1959.

23. H. Ehringer, C. Mongini-Tamagnini, and C. Ponti, "Thermocouple Composition Changes Due to Neutron Irradiation," European Atomic Energy Community, EUR-3156e, 1966.

24. N. H. Hancock, "The Use of Noble and Refractory Metal Thermocouples in Experimental Irradiation Equipment," Proc. Internaional. Symposium On Developments in Irradiation Capsule Technology, D.R. Hoffman, ed., Joint AEC/GE Meeting, 1967.

25. J.W. Helm, "Irradiation Effects on Thermocouples," Proc. International Symposium On Developments in Irradiation Capsule Technology, D. R. Hoffman, ed., Joint AEC/GE Meeting, 1967.

26. See, for example, Neutron Cross Sections, BNL-325, Second Edition, Brookhaven National Laboratory, Feb 1965.

27. C. Vitanza and T. E. Stien, "Assessment of Fuel Thermocouple Decalibration During In-Pile Service," Journal of Nuclear Materials, Vol. 139, p. 11, 1986.

28. F. A. Reichardt, "Measurement of High Temperatures Under Irradiation Conditions," Platinum Metals Rev., Vol. 7, p. 122, 1963.

29. G. W. Cunningham and W. H. Goldthwaite, "Contribution to the Meeting on High Temperature Thermometry,” WASH-1067, Paper 25, 1966.

30. Private communication, June 1986.

31. S. Fanciullo, "Thermocouple Development, Lithium Cooled Reactor Experiment," Pratt and Whitney Aircraft, PWAC-422, 1964.

32. G. E. Pletenetskii, "Thermocouples for Measuring High Temperatures in a Vacuum," Instruments and Experimental Techniques, Vol. 1, p. 214, 1967.

33. E. D. Zysk and A. R. Robertson, "Newer Thermocouple Materials," Temperature: Its Measurement and Control in Science and Industry, Vol. 4, Part 3, p. 1697, 1971. 
34. S.C. Wilkins, "Characterization and Materials-Compatibility Tests of Molybdenum-Niobium Thermocouples," Temperature: Its Measurement and Control in Science and Industry, Vol. 6, Part 1, p. 627, 1992.

35. R. C. Knight and D. L. Greenslade, "Irradiation Testing of a Niobium-Molybdenum Developmental Thermocouple," Westinghouse Hanford Technical Report WHC-SA-1256FP, 1991.

36. J. L. Rempe and S.C. Wilkins, "Specialized Thermocouples for High Temperature In-Pile Applications," INEEL/EXT-03-00378, 2005.

37. C. Crussard, "Thermoelectric Properties of Metals - Influence of Cold Work and Impurities," in Report of Conference on Strength of Solids, Physical Society of London, p. 119, 1948.

38. G. Glock, G. Metauer, R. Schley, and M. Gantois, "Nouveaux alliages thermoélectriques destinés à la mesure des températures en pile," Rev. Int. Hautes Tempér. Réfract., Vol. 15, p. $159,1978$.

39. J. K. Partin, "Radiation Effects - Testing of Optical Fibers in a Nuclear Reactor," Space Nuclear Power Systems, Chapter 33, 1985.

40. J. K. Partin, "Fiber Optics in High Dose Radiation Fields," Radiation Effects in Optical Materials, p. 541, 1985. 